\title{
Review Article \\ Structural Characterization of Lignin and Its Degradation Products with Spectroscopic Methods
}

\author{
Yao Lu, ${ }^{1,2,3}$ Yong-Chao Lu, ${ }^{4}$ Hong-Qin Hu, ${ }^{3}$ Feng-Jin Xie, ${ }^{3}$ Xian-Yong Wei, ${ }^{1,3}$ and Xing Fan ${ }^{1,3}$ \\ ${ }^{1}$ Key Laboratory of Coal Processing and Efficient Utilization, Ministry of Education, China University of Mining \& Technology, \\ Xuzhou 221116, China \\ ${ }^{2}$ Advanced Analysis \& Computation Center, China University of Mining \& Technology, Xuzhou 221116, China \\ ${ }^{3}$ School of Chemical Engineering and Technology, China University of Mining \& Technology, Xuzhou 221116, China \\ ${ }^{4}$ School of Basic Education Sciences, Xuzhou Medical University, Xuzhou 221004, China \\ Correspondence should be addressed to Xing Fan; fanxing@cumt.edu.cn
}

Received 19 July 2017; Accepted 3 October 2017; Published 29 November 2017

Academic Editor: Javier Garcia-Guinea

Copyright (C) 2017 Yao Lu et al. This is an open access article distributed under the Creative Commons Attribution License, which permits unrestricted use, distribution, and reproduction in any medium, provided the original work is properly cited.

\begin{abstract}
Lignin is highly branched phenolic polymer and accounts $15-30 \%$ by weight of lignocellulosic biomass (LCBM). The acceptable molecular structure of lignin is composed with three main constituents linked by different linkages. However, the structure of lignin varies significantly according to the type of LCBM, and the composition of lignin strongly depends on the degradation process. Thus, the elucidation of structural features of lignin is important for the utilization of lignin in high efficient ways. Up to date, degradation of lignin with destructive methods is the main path for the analysis of molecular structure of lignin. Spectroscopic techniques can provide qualitative and quantitative information on functional groups and linkages of constituents in lignin as well as the degradation products. In this review, recent progresses on lignin degradation were presented and compared. Various spectroscopic methods, such as ultraviolet spectroscopy, Fourier-transformed infrared spectroscopy, Raman spectroscopy, and nuclear magnetic resonance (NMR) spectroscopy, for the characterization of structural and compositional features of lignin were summarized. Various NMR techniques, such as ${ }^{1} \mathrm{H},{ }^{13} \mathrm{C},{ }^{19} \mathrm{~F}$, and ${ }^{31} \mathrm{P}$, as well as $2 \mathrm{D}$ NMR, were highlighted for the comprehensive investigation of lignin structure. Quantitative ${ }^{13} \mathrm{C}$ NMR and various $2 \mathrm{D}$ NMR techniques provide both qualitative and quantitative results on the detailed lignin structure and composition produced from various processes which proved to be ideal methods in practice.
\end{abstract}

\section{Introduction}

The main components of lignocellulosic biomass (LCBM) are cellulose, hemicellulose, and lignin. Cellulose is a polymer of glucose, accounting for 30-50 wt\% of dry LCBM; hemicellulose is a mixture of heteropolymers containing various polysaccharides, such as xylan, glucuronoxylan, and glucomannan, accounting for 20-35 wt\%; the mainly remaining portion with $15-30 \mathrm{wt} \%$ is lignin, which is a multisubstituted phenolic polymer. Lignin is the most abundant aromatic biopolymer accounting for up to $30 \%$ of the organic carbon on Earth and thus can be treated as a potential renewable feedstock for energy supplement and aromatic chemicals production $[1,2]$. The annual production of lignin is more than 70 million tons [3]. The most abundant industrial lignins are produced from kraft and sulfite pulping processes in the pulp and paper industries, so-called black liquor. However, only less than $2 \%$ of the lignin produced from pulping industries was value-addedly utilized, while the rest was abandoned or burned as a low-value fuel for energy supplement [4], leading to serious waste of precious aromatic resource and environmental pollution.

Lignin is an amorphous, irregular three-dimensional, and highly branched phenolic polymer. The functions of lignin in the plant cell wall are to cover structural support, transport water and nutrients, and issue protection to prevent chemical or biological attacks, and so forth. Though the chemical structure is extremely complex, it is generally accepted that lignin is formed via irregular biosynthesis process constructed from three basic phenylpropanoid monomers, 


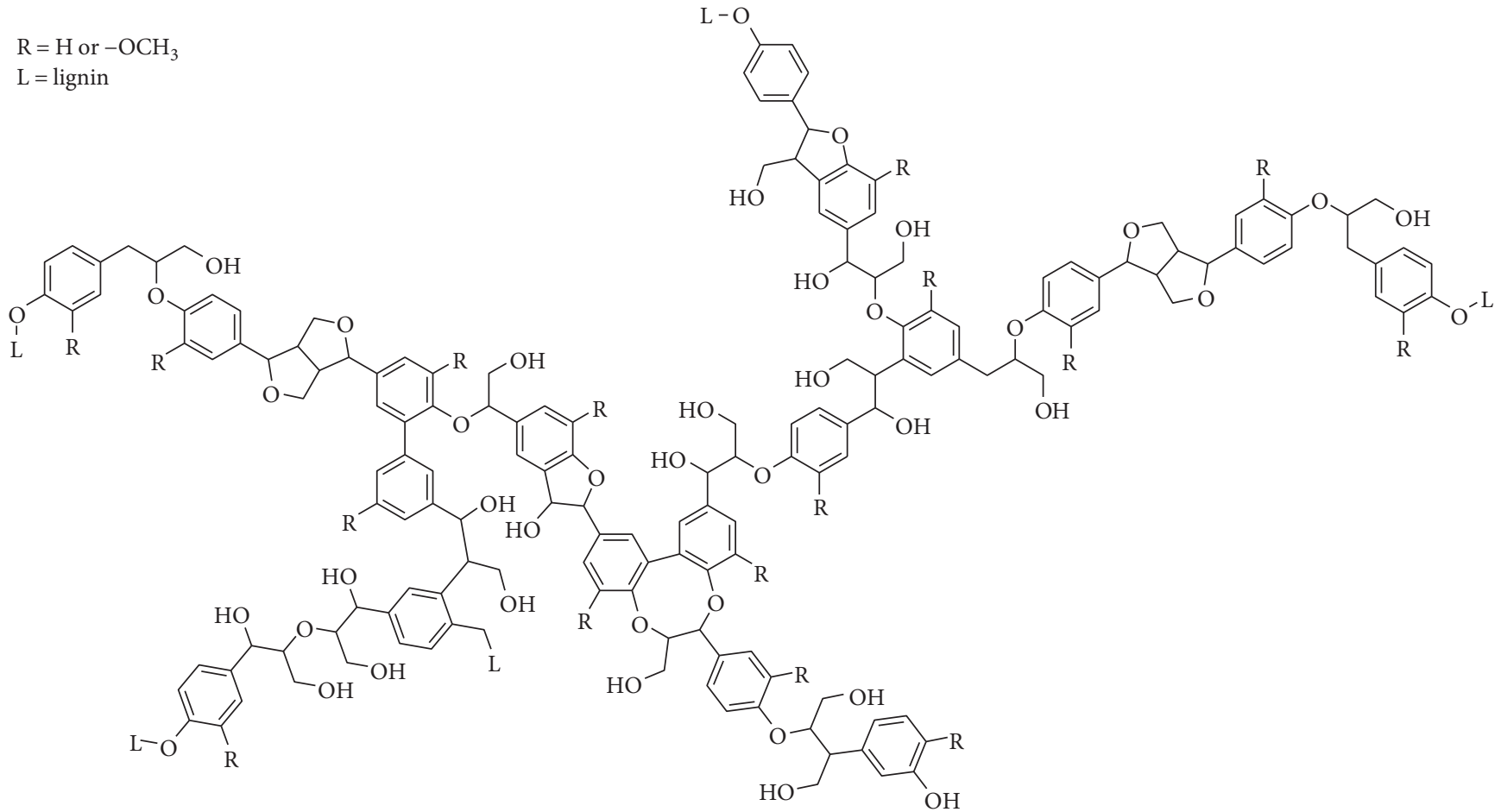

Figure 1

p-hydroxyphenyl $(\mathrm{H})$, guaiacyl $(\mathrm{G})$, and syringyl (S) units, derived from $p$-coumaryl, coniferyl, and sinapyl alcoholic precursors, respectively. Figure 1 shows a typical structural model of lignin. Gymnosperms contain almost entirely $\mathrm{G}$ unit in lignins; dicotyledonous angiosperms contain G and $\mathrm{S}$ units in lignins; and all the $\mathrm{G}, \mathrm{S}$, and $\mathrm{H}$ units can be found in monocotyledonous lignins [5]. Other units with relatively fewer contents were also identified in the lignin of LCBM, such as ferulates and coumarates [6]. Biosynthesis of lignin is a process that monomers undergo radical coupling reactions to form racemic, cross-linked, and phenolic polymer, by which lignin content and composition may vary significantly in different LCBMs [7]. Furthermore, the structure of lignin even varies among different tissues and ages of the same individual of LCBM [8].

Typical lignin contents are $24-33 \%$ in softwoods, $19-28 \%$ in hardwoods, and $15-25 \%$ in grasses, respectively. Functional groups in lignin include methoxyl, carbonyl, carboxyl, and hydroxyl linking to aromatic or aliphatic moieties, with various amounts and proportions, leading to different compositions and structures of lignin [9]. Various linkages (see Figure 2) either in C-C or C-O type with different abundances formed in the coupling reactions involved in biosynthesis of lignin, including aryglycerol- $\beta$-ether dimer ( $\beta$-O- $4,45-50 \%)$, biphenyl/dibenzodioxocin $\left(5-5^{\prime}, 18-25 \%\right)$, pino/resinol $(\beta-5,9-12 \%)$, diphenylethane $(\beta-1,7-10 \%)$, aryglycerol- $\alpha$-ether dimer ( $\alpha$-O-4, $6-8 \%)$, phenylcoumaran $\left(\beta-\beta^{\prime}, 0-3 \%\right)$, siaryl ether $(4-\mathrm{O}-5,4-8 \%)$, and spirodienon.

It is difficult to draw accurate structural diagram for entire lignin by using up-to-date techniques in situ. Although relative new methods for imaging and analyzing chemical structure of lignin, such as confocal Raman scattering microscopy [10] and time-of-flight secondary ion mass spectrometry [11, 12], can provide chemical and spectral imaging of lignin for the distribution of componential units with high resolution and sensitive, these techniques are only available in several biological labs and have not been employed widely by chemical scientific groups. Up to now, the comprehensive elucidation of structural and compositional features of lignin relies on the processes for the degradation and isolation of lignin from LCBM and methods applied in the characterization of the corresponding products $[2,13]$. However, in the degradation process, the original structural and compositional features of lignin may be sometimes ambiguous or even missed. Different degradation processes produce different types of lignins with various structures and compositions; furthermore, a specific analytical technique gives partial and/ or limited information and is not able to provide a general picture for the entire lignin. The industrial applications of lignin are limited critically due to its complex nature and undefined chemical structure. For example, commercially purchased kraft lignins from softwoods may have different compositions as well as their structures [14]. Furthermore, the lignin-carbohydrate complex (LCC) increases the difficulty of structural analysis and isolation of lignin from LCBM [15]. The value-added utilization of lignin and its degradation products are one of the ultimate goals especially for biorefineries; therefore, the comprehensive understanding of the structure of lignin is crucial necessary, since it can provide theoretical direction on constructing and optimizing degradation processes, generating of valuable aromatic chemicals 
<smiles>[R]c1cc(C2OCC3C(c4cc([R])c(O[Tl])c([R])c4)OCC23)cc([R])c1O[Tl]</smiles>

$\mathrm{R}=\mathrm{H}$ or $\mathrm{f}-\mathrm{OCH}_{3}$ $\mathrm{L}=$ Lignin<smiles>[R]c1cc(I)cc(C(CO)C(O)c2cc([R])c(O[3H])c([R])c2)c1O</smiles><smiles>C1=[As]C[As]=1</smiles><smiles>OC/C=C/c1ccc(O)cc1</smiles>

p-Coumaryl<smiles>[R]c1cc(C(O)C(CO)Oc2c([R])cc(I)cc2[R])cc([R])c1O[Tl]</smiles><smiles>[R]c1cc(C(O)C(CO)c2cc([R])c(O)c([R])c2)cc([R])c1O</smiles>

$\beta-1$

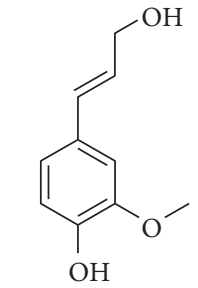

Coniferyl alcohol

Guaiacyl, G<smiles>[R]c1cc(I)cc(-c2cc(I)cc([R])c2OC)c1O</smiles><smiles>COc1cc(/C=C/CO)cc(OC)c1O</smiles><smiles>C=C</smiles>
$\mathrm{HO}$<smiles>[R]c1cc(C2Oc3c([R])cc(I)cc3-c3cc(I)cc([R])c3OC2CO)cc([R])c1O[Tl]</smiles>

Dibenzodioxocin

Sinapyl alcohol<smiles>[Y]c1cc([R])c(Oc2cc(I)cc([R])c2O)c([R])c1</smiles>

Figure 2

to act as low-molecular-mass feedstocks [16], estimating the economic viability, and so forth.

Traditionally, there are two ways to isolate lignin from other components in LCBM, so-called degradation processes: one is to extract cellulose and hemicellulose leaving most of the lignin as solid residue, and the other one is to extract lignin by using fractionation methods leaving the other components. For the former process, dilute sulfuric acid and hot water are often used to break down cellulose and hemicellulose releasing sugars and facilitating the further enzymatic hydrolysis, while leaving lignin as the main content in solid residue. For the later process, hydroxide solution, either with sodium, potassium or calcium, is used to remove lignin from LCBM samples. The degradation processes are designed to cleave the bonds between lignin and carbohydrates, leading to more or less extensive changes compared to native lignin structure. Consequently, the chemical compositional features of the resulting technical lignins, such as the relative abundance of $\mathrm{S} / \mathrm{G} / \mathrm{H}$ units, the status of side chains, and the contents of functional groups, are highly dependent on the methods and conditions used in degradation processes [17]. The most common linkages in lignin, namely, $\beta-\mathrm{O}-4$ linkages, are relatively weak linkages and are the key target of most degradation pretreatments. Other linkages, such as $\beta-5, \beta-1, \beta-\beta^{\prime}, 5-5^{\prime}$, and $4-\mathrm{O}-5$, are more complicated and difficult to be degraded. Toward the structural investigation, various lignins are produced via different degradation processes, such as milled wood lignin (MWL), acidic lignin, sulfite lignin, soda lignin, kraft lignin, organosolv lignin, cellulolytic enzyme lignin (CEL), enzymatic mild acidolysis lignin (EMAL), and lignin from thioacidolysis process [2]. In the recent years, extraction and depolymerization with ionic liquids (ILs) for the isolation or degradation of lignins were considered to be promising processes $[18,19]$.

For the structural and compositional elucidation of complex samples, various instrumental methods were used. For example, the chromatographic techniques coupled to mass spectrometers and high-resolution mass spectrometric techniques were used extensively in the analysis of the bio-oil, biomass, and lignin samples [20-24]. These methods concentrate on the detection of individual species basing on the chromatographic separation and high molecular resolution. However, on the other hand, spectroscopic methods, such as ultraviolet spectroscopy (UV), Fourier-transformed infrared spectroscopy (FTIR), and nuclear magnetic resonance 
(NMR), concern about the analysis of the whole structure and direct detection of moieties in samples over degradation techniques $[25,26]$. Detailed spectrometric information related to structural features, including functional groups, bond types, and chemical state of atoms, can be obtained. Furthermore, both of the qualitative and quantitative analyses can be carried out simultaneously.

In this review, we focused on the recent development and interesting findings on the structural investigation of lignin with spectroscopic methods over various degradation processes. Structural and compositional characters of lignin samples produced from different degradation processes were presented and compared, and developments of spectroscopic methodologies on the qualitative and quantitative elucidation of lignin structure were also summarized. The degradation processes and instrumental methods involved in the detailed and comprehensive understanding of the lignin structure were prospected.

\section{Degradation Processes of Lignin}

Various physical/chemical methods were carried out for the degradation and isolation of lignin. Optimization or modification of these methods was conducted on various LCBMs due to the difference in the structure of lignin. In order to facilitate further structural and/or compositional analyses or to produce high purity lignin, modified or multistep processes were usually carried out.

2.1. Milled Wood Lignin. MWL is produced via the extraction of milled sample particles from LCBM with a neutral organic solvent (e.g., 1,4-dioxane) under mild conditions to remove other components. In the extraction process, only minor changes may occur with respect to the milled sample; hence, the obtained lignin has similar property with the milled sample. Nevertheless, MWL is not considered to be a representative of the original lignin in the LCBM due to its relative low yield (based on Klason lignin).

2.2. Cellulolytic Enzyme Lignin. In order to improve the yield, CEL was developed from the extraction of enzymatically hydrolyzed MWL residue. Typically, the residual carbohydrate contents in CEL account $10-15 \mathrm{wt} \%$ of initial MWL sample. The structure of CEL is similar to MWL, and it is more representative of total lignin in LCBM than in MWL. CEL has commonly been used for the structural analysis of lignin in the cell wall of plants. In a recent study, cellulolytic enzyme hydrolysis was carried out prior to water/dioxane extraction of MWL to remove carbohydrates. The lignin was obtained with high yield and purity [27]. Enzymatic lignin degradation has several advantages such as mild conditions and potentially fewer inhibitors for microbes. However, the degradation of lignin in LCBM still gave a very low yield of fragmented and soluble lignin, which may due to the limitations on efficient electron transfer [28] in the process.

2.3. Sulfite, Soda, and Kraft Lignins. Sulfite, soda, and kraft lignins are by far the main technical lignins produced via industrial processes. Among them, sulfite and kraft methods are sulfur-involving processes, accounting more than $90 \%$ of the chemical pulp production worldwide [29], and soda method is sulfur-free process. In the sulfite process, watersoluble lignosulfonates are formed. Further purification is needed to remove unexpected carbohydrate impurities. This process produces the largest amount of technical lignin. However, the obtained lignin contains considerable amount of sulfur. In the soda process, lignin is dissolved in hydroxide solution and following steps including precipitation, maturation, and filtration. In the kraft process, LCBM particles are emerged in an aqueous solution containing $\mathrm{NaOH}$ and $\mathrm{Na}_{2} \mathrm{~S}$. Lignins are depolymerized as water-/alkali-soluble fragments with approximately $70-75 \%$ of the hydroxyl groups become sulfonated. Industrially, kraft lignin, produced chemically from the lignin degradation in aqueous alkali, is the major constituent of black liquor (90-95\%). Neither kraft lignin nor sulfite lignin is suitable for investigating the original native structures of lignins, because significant structural changes occur especially the cleavage of $\alpha-\mathrm{O}-4$ and $\beta-\mathrm{O}-4$ linkages under the conditions of these processes. Additionally, undesirable impurities such as sulfurous compounds or carbohydrates are present in derived lignin for these fractionation processes. Currently, almost all the produced technical lignins are only high yield industrial by-products and recovered as low-value fuel. This dilemma may rely on the progress in structural characterization of lignins from various LCBMs and the further upgrading of the technical lignins targeting value-added chemical production.

2.4. Organosolv Lignin. In the organosolv process, high purity lignin and cellulose are produced at the same time with various solvents; however, no technical lignins are commercially available from this process up to now. Organosolv process typically results in more than 50\% lignin removal from LCBM through cleavage of lignin-carbohydrate bonds and $\beta$-O-4 linkages. The separation of organosolv lignin can be achieved either by removing of the solvent or by precipitation with water followed by distillation. Most organosolv lignin is easily soluble in basic solutions and polar solvents, that is, ethanol or ethanol/water mixture, but will be insoluble in acidic aqueous solutions. Organosolv lignin is sulfur-free, high purity, and rich in functionality including phenolics, exhibits a narrow polydispersity, and has limited carbohydrate contamination.

The extraction conditions affect the structure of organosolv lignin, that is, severity factor ( $\mathrm{H}$-factor). The molecular weight of the ethanol organosolv lignin decreased within a $36-56 \%$ range with respect to the MWL with the increase of the severity. Moreover, an obvious decrease in the content of aliphatic hydroxyl groups and an increase of syringyl phenolic units and condensed phenolic structures with the increase in severity of the organosolv treatment were also observed [30]. An integrated process of hot water extraction followed by high-boiling-solvent cooking with 1,4-butanediol can fractionate bagasse vigorously into cellulose, hemicelluloses, and lignin. The organosolv lignin formed exhibited a chemical structure similar to EMAL with more newly formed phenolic OH groups [31]. 
2.5. Acidic Lignin. Traditionally, in the acidolysis process, lignin is extracted from LCBM sample with 1,4-dioxane containing hydrochloric acid under room temperature. The obtained lignin with high purity is considered to be a representative of the original lignin. However, a limitation of this process is that the same conditions used to hydrolyze polysaccharides also degrade the liberated monosaccharides, leading to overestimate monosaccharide degradation and introducing bias between polysaccharides of different liability. Modifications were introduced to reduce these errors [32]. A modified acidolysis process was carried out by Gong et al. [33]. The acetic acid lignin from bamboo shoot shell had a higher yield of lignin (74 wt\%) and lower content of associated carbohydrates (2.96 wt\%) than MWL (5.16 wt\%). Additionally, acetic acid lignin possessed a molecular weight $2789 \mathrm{Da}$ and a narrow polydispersity index (i.e., $M_{\mathrm{w}} /$ $\left.M_{\mathrm{n}}=1.54\right)$. Higher phenolic hydroxyl group content and S/ $\mathrm{G}$ ratio were also obtained in this lignin compared to MWL [33]. Enzymatic mild acidolysis lignin (EMAL) is obtained from acidolysis of CEL with dilute acid, such as hydrochloric acid. The remaining carbohydrates linking to lignin can be removed further in the acidolysis producing lignin with higher purity [34].

2.6. Thioacidic Lignin. Modified acidolysis processes were carried out to produce lignin with high yield and purity. Thioacidolysis process, in which ethanethiol is used instead of water, produced more lignin and less complex monomer mixtures. In this process, thioethylated $\mathrm{H}, \mathrm{G}$, and $\mathrm{S}$ monomers by the cleavage of $\beta$-O- 4 ether linkages are produced. Traditional thioacidolysis methods require several steps before down streaming analysis or further treatments. Hence, higher-throughput quantitative method is needed for screening various types of LCBMs [35].

2.7. Ionic Liquid Degradation Lignin. IL provides an alternative path for lignin removal to classic organosolv pretreatment for enhancing subsequent enzymatic hydrolysis and isolation. Some ILs, such as 1-ethyl-3-methylimidazolium acetate, can extract lignin from poplar and birch with most structural features retained [36]. Some acidic ILs, such as 1-H-3-methylimidazolium chloride, will hydrolyze ether linkages [37] and further degrade lignin. The following are some recent progresses concentrated on the lignin degradation and isolation by ILs.

The ILs containing 1-butyl-3-methylimidazolium (bmim), 1-ethyl-3-methylimidazolium (emim), and 1-allyl3-methylimidazolium (amim) cations either with acetate or chloride as the anions are commonly used in the lignin dissolution [38]. ILs have the capability to disrupt various linkages between the components in the LCBM by the formation of several types of interactions such as hydrogen bond, dipoledipole, and van der Waals interactions [39]. Pyridinium formate (PyFor) showed a high capacity for the dissolution of kraft lignin $(70 w / w \%)$ at a relatively lower temperature $\left(75^{\circ} \mathrm{C}\right)[40]$.

Cholinium ILs are novel bio-ILs used in the lignin valorization, in which different chemical reactions take place during the lignin dissolution from imidazolium ILs [41]. In the dissolution of kraft lignin in cholinium ILs, significant changes in the structure and thermal properties of kraft lignin occurred via depolymerization, dehydration, and demethoxylation followed by recondensation. Thermal properties of kraft lignin were altered, that is, increased the maximal decomposition temperature $\left(T_{\mathrm{m}}\right)$ and glass transition temperature $\left(T_{\mathrm{g}}\right)$; and the molecular weights were reduced after regeneration from cholinium ILs [41].

Other ILs, such as 1-ethyl-3-methylimidazolium xylenesulfonate [emim][ABS] and 1-butyl-3-methylimidazolium methylsulfate $[\mathrm{bmim}]\left[\mathrm{MeSO}_{4}\right]$, could promote depolymerization of organosolv lignin and Klason lignin under the oxidative conditions using a $\mathrm{Cu} / \mathrm{EDTA}$ complex in the presence of a monomeric phenol (4-tert-butyl-2,6-dimethylphenol) [42].

An acidic IL, called 1-(4-sulfobutyl)-3-methyl imidazolium hydrosulfate $\left(\left[\mathrm{C}_{4} \mathrm{H}_{8} \mathrm{SO}_{3} \mathrm{Hmim}\right] \mathrm{HSO}_{4}\right)$, was proven to be an efficient catalyst for direct liquefaction of bagasse lignin, where more than $65 \%$ degree of liquefaction and $13.5 \%$ yield of phenolic monomer without any char formation [43].

A switchable ionic liquid (SIL), synthesized from 1,8diazabicyclo[5.4.0] undec-7-ene (DBU), monoethanol amine (MEA), and $\mathrm{CO}_{2}$, named $\mathrm{CO}_{2}$-switched [DBU][MEASIL], was demonstrated to have high ability to extract the interlinked polysaccharide impurities from the sodium lignosulfonate while the linkages and aromatic subunits remain unaffected during the dissolution-recovery cycle. This SIL can be used as an affordable solvent medium to obtain carbohydrate-free lignin from an impure lignin source [44].

Future developments on the IL degradation of lignin will focus on selective lignin extraction/degradation and functionalization as well as minimization of process costs for recovery and recycling of ILs.

2.8. Multistep Processes. Multistep processes were used to enhance the removal of lignin. A two-step process was carried out in which anhydrous ammonia pretreatment was followed by mild $\mathrm{NaOH}$ extraction on corn stover to solubilize and fractionate lignin [45]. Lignin removal of more than $65 \%$ with over $84 \%$ carbohydrate retention was achieved. Furthermore, a significant reduction in the weight-average molecular weight $\left(M_{\mathrm{w}}\right)$ of extracted lignin was also achieved. Synergistic effects were found in the combination of pretreatments to enhance the isolation or conversion of lignins $[28,46]$. In the sequential fractionation of Tamarix spp., MWL, organosolv lignin, and alkaline lignin were conducted with dioxane, alkaline organosolv, and alkaline solutions, respectively. The results indicated that the alkaline organosolv extraction released a higher yield of lignin $(17.7 \%)$ than dioxane and alkaline solution extractions. Small amounts of carbohydrates $(0.79 \%)$ were detected in the organosolv lignin fraction, suggesting a significant cleavage of $\alpha$-ether bonds between lignin and carbohydrates in the alkaline organosolv fractionation process [47].

2.9. Comparison of the Processes. Alkaline lignins were found to have higher carbohydrate content (up to $30 \mathrm{wt} \%$ ) with higher molecular weights around $3000 \mathrm{Da}$; on the other hand, organosolv lignins had considerable high purity (better than 
$93 \mathrm{wt} \%$ ) with molecular weights in the range of 600-1600 Da [48]. The structure and composition of alkali lignin, CEL, and MWL from valonea of Quercus variabilis Blume were compared by Yang et al. [49]. The isolation processes of alkali lignin and CEL caused some damages to the structure of lignin. The $\beta$-O-4 linkages were largely cleaved during the CEL process since the relative content of $\beta$-O-4 linkages in CEL was much lower than those in alkali lignin and MWL. High S/G ratio for alkali lignin was observed, indicating that the S-units were easily released under the alkali conditions.

Yang et al. [50] compared four lignins produced from valonea of Quercus variabilis, namely, ethanol lignin, alkali lignin, MWL, and enzyme hydrolysis lignin (EHL). The results showed that the four lignins contained GSH-type with little differences. The MWL contained the least functional groups with the poorest thermostability and the highest antioxidant activity. The EHL had the highest molecular weight (i.e., $M_{\mathrm{w}}=1429 \mathrm{~g} / \mathrm{mol} ; M_{\mathrm{n}}=746.18 \mathrm{~g} / \mathrm{mol}$ ). In a comparison of pretreatments on hardwood (red oak), softwood (loblolly pine), and herbaceous biomass (corn stover) for lignin valorization through pyrolysis, organosolv lignins contained fewer volatiles in comparison to the corresponding MWLs for all the tested samples [51]. Red oak lignin was affected mostly by the organosolv process, since the greatest decrease in volatile content and increase in carbon content were observed. Corn stover lignin had the highest potential for volatilization because it retained highly branched polymer structure enriched in tricin, ferulate, and coumarate groups.

Clearly, different degradation processes or pretreatments have significant influence on the compositional and structural features of lignin. The selectivity and efficiency of these processes are the main consideration. To elucidate the original structure of lignin, relatively undestroyed and effective degradation methods are feasible, such as IL extraction and organosolv process. To produce value-added chemical from lignin, more aggressive methods aiming at the cleavage of the weak linkages in lignin (i.e., $\beta$-O-4 linkages) and the interunits between lignin and polysaccharides can be used in the degradation process. Of course, biological conversion with suitable selectivity might be another orientation for degradation of lignin [52].

\section{Spectroscopic Methods}

Structural investigation of lignin with spectroscopic techniques has been considered to be promising high-throughput and routine methods, which can provide detailed qualitative and quantitative information on structural features including functional groups, types of chemical bonds, and states of atoms.

3.1. UV Spectroscopy. The content of acid-soluble lignin, the purity, and the components of isolated lignin, can be determined by using UV spectroscopy [53]. National Renewable Energy Laboratory (NREL) proposed an accurate method for the determination of lignin, by which the absorbance of lignin was recorded at the recommended wavelength [54]. According to the intrinsic structure of lignin, several absorption maxima attributed to different functional groups were
TABLE 1: UV spectroscopic absorptions of typical structures in lignin $[25,30,50,53-56]$.

\begin{tabular}{|c|c|c|}
\hline $\begin{array}{l}\text { Absorption } \\
\text { maxima/nm }\end{array}$ & $\begin{array}{c}\text { Electronic } \\
\text { transition style }\end{array}$ & Chromophores and structures \\
\hline 200 & $\pi-\pi^{*}$ & Conjugated bonds/aromatic ring \\
\hline 240 & $n-\pi^{*}$ & Free $-\mathrm{OH}$ \\
\hline 282 & $\pi-\pi^{*}$ & Conjugated bonds/aromatic ring \\
\hline 320 & $\pi-\pi^{*}$ & $\begin{array}{l}\text { Aromatic ring conjugated bond } \\
\text { with } C=C\end{array}$ \\
\hline 320 & $n-\pi^{*}$ & $\begin{array}{c}\mathrm{C}=\mathrm{O} \text { groups conjugated to } \\
\text { aromatic ring }\end{array}$ \\
\hline 325 & $n-\pi^{*}$ & Etherified ferulic acid \\
\hline
\end{tabular}

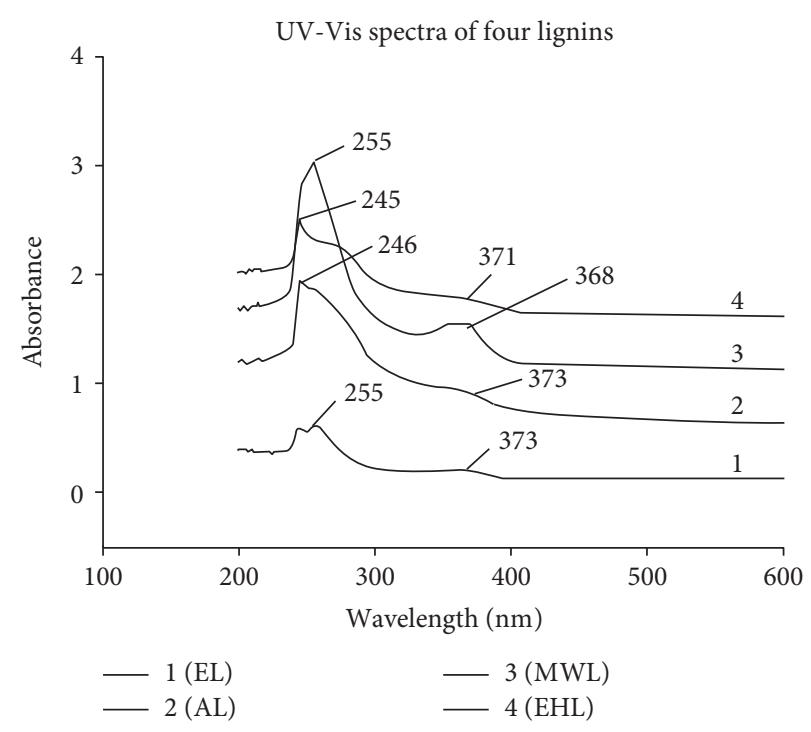

Figure 3

observed, as shown in Table $1[25,30,50,53-56]$. The determination of phenolic hydroxyl groups can be achieved basing on the difference in absorption at 292 and $370 \mathrm{~nm}$ between phenolic units in neutral and alkaline solutions $[30,50,55,56]$. Attributed to the symmetrical syringyl unit, the maximum absorbance of lignins produced from different processes exhibited a blue shift. Furthermore, an additional absorbance at approximately $370 \mathrm{~nm}$ due to the presence of conjugated phenolic hydroxyl groups was also observed [50] (see Figure 3).

Basing on the Lambert-Beer's Law, UV spectroscopy can be used for the semiquantitative determination of the purity of lignin and its degradation products by using extinction coefficient (EC) $[57,58]$. Because of the cross-linking structures of lignin with carbohydrates, cellulose, and hemicelluloses, the isolation of pure lignin is extremely difficult. The low value of EC represents the high nonlignin substance content in the isolated lignin.

3.2. FTIR Spectroscopy. FTIR spectroscopy is the most widely used technique in the functional group determination basing 


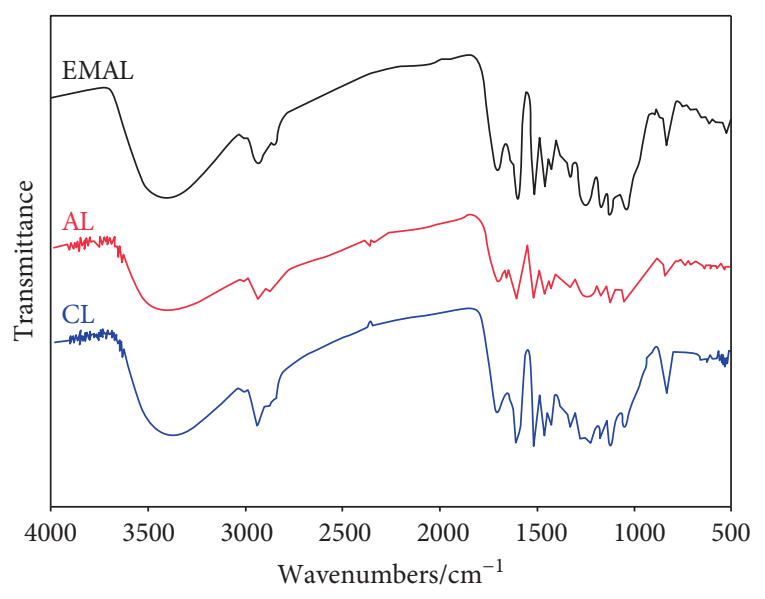

FIGURe 4

on the substances with chromophores. It can be treated as a nondestructive, noninvasive, highly sensitive, and rapid technique. Typical functional groups contained in lignin, such as hydroxyl, carbonyl, methoxyl, carboxyl, and aromatic and aliphatic $\mathrm{C}-\mathrm{H}$, can be assigned well in the FTIR spectrum. Figure 4 shows FTIR spectra for detection of different lignins, namely, EMAL, autocooking lignin (AL), and citric acid-catalyzed cooking lignin (CL) [31]. For the assignments of signals in FTIR spectra, Table 2 lists the typical wavelength assigned for possible functional groups and structures in lignin $[25,29,38]$.

Attenuated total reflectance- (ATR-) FTIR could be used for the evaluation of kraft lignin in acylation with different acyl chlorides [59] and lignin structural changes during the cooking process with solid alkali and active oxygen [60]. FTIR spectroscopy could also characterize changes in the chemical structure of wood polymers in relation to the tree growth location and conditions [61]. Untreated solid samples (Norway spruce, P. abies L. Karst.) from three provenances in Europe were selected. Principal component analysis (PCA) and cluster analysis (CA) were used for evaluation of spectral data obtained by FTIR spectroscopy. The results showed that the samples belonging to the same wood species differ due to the origin. FTIR analysis was able to correctly discriminate samples originating from three different provenances in Europe.

It is known that functional properties of oxyethylated lignins (OELs) and the resulting substances are strongly affected by the degree of oxyethylation (DOE) of phenolic hydroxyl groups $\left(\mathrm{OH}_{\text {phen }}\right)$. Passauer et al. [62] found the strong linear correlations between $\mathrm{OH}_{\text {phen }}$ contents of lignin/OEL and FTIR vibrations attributed to phenolic and aliphatic acetoxy groups. With appropriate calibration, FTIR spectroscopy combined with sample preacetylation is considered to be a promising tool for rapid and accurate determination of the DOE of OELs with qualitative and quantitative results.

3.3. Raman Spectroscopy. Raman spectroscopy, as the sister spectroscopic technique of FTIR, can provide complementary information on the structural features even for the samples containing water. Furthermore, more absorption bands were detected with Raman spectroscopy than FTIR [63]. Generally, the assignments of the absorption bands in Raman spectra are similar with FTIR spectra.

Raman spectroscopy is suitable for the investigation of the chemical structure of lignin, because it can provide in situ determination on the cell wall of plants even with no sample preparation. However, when analyzing a lignin sample in solutions with various solvents, one should consider the environmental effects of the solvents [64]. Confocal Raman microscopy was used to investigate the structural changes of lignocellulosic cell walls during the dilute acid pretreatments. According to the intensity of the Raman images, the ratio of lignin/cellulose $\left[\mathrm{I}\left(1600 \mathrm{~cm}^{-1}\right) / \mathrm{I}\left(900 \mathrm{~cm}^{-1}\right)\right]$ was low for oxalic acid-pretreated biomass compared to sulfuric acid-pretreated biomass [65].

3.4. NMR Spectroscopy. NMR spectroscopy provides more precise and comprehensive information on qualitative and quantitative assays for the frequencies of linkages and the composition of H/G/S units in the lignin analysis. The first discovery of dibenzodioxocine and spirodienone structures in lignin was carried out by Ralph et al. [66] and Zhang et al. [67], respectively. ${ }^{1} \mathrm{H},{ }^{13} \mathrm{C},{ }^{19} \mathrm{~F}$, and ${ }^{31} \mathrm{P}$ as well as various 2D NMR spectroscopic techniques can be used in the structural and compositional analyses of lignin. Among them, ${ }^{1} \mathrm{H}$ and ${ }^{13} \mathrm{C}$ NMR tend to be the regular tools for the analysis of lignin; and solid-state ${ }^{13} \mathrm{C}$ NMR and $2 \mathrm{D}$ heteronuclear single-quantum coherence (HSQC) NMR can provide accurate quantitative results on the functional groups and side chain moieties.

Compared with the spectroscopic methods mentioned above, NMR spectroscopic methods possess much higher resolution and enable a larger amount of information to be obtained. One-dimensional (1D) NMR methods, including ${ }^{1} \mathrm{H},{ }^{13} \mathrm{C},{ }^{19} \mathrm{~F}$, and ${ }^{31} \mathrm{P}$ NMR, and two-dimensional (2D) NMR methods, such as 2D HSQC NMR, were applied for the analysis of lignin samples with both solid and liquid states. The distribution of functional groups and amount of linkages and H/G/S units as well as other components in lignin can be qualitatively and quantitatively determined. The chemical shifts of functional groups in the spectra have been established.

${ }^{1} \mathrm{H}$ NMR is the method routinely used in the structural investigation of lignin, because of the simple preparation of samples and fast scanning speed. Almost all the compositional investigations of lignins use ${ }^{1} \mathrm{H}$ NMR for the detection of the chemical environment of proton. In the spectra, the signal observed around $7.5 \mathrm{ppm}$ can be assigned to aromatic protons of $\mathrm{H}$ units and the other two chemical shifts around $7.0 \mathrm{ppm}$ and $6.5 \mathrm{ppm}$ are attributed to aromatic protons in $\mathrm{G}$ and $\mathrm{S}$ units, respectively $[68,69]$. The chemical shifts in the range of $6.3-4.0 \mathrm{ppm}$ are assigned to aliphatic protons in the linkages of $\beta-O-4, \beta-\beta$, and $\beta-5$. The signals in the range of $4.0-3.5 \mathrm{ppm}$ are attributed to protons in methoxyl groups. The chemical shifts around $3.10 \mathrm{ppm}$ may be attributed to the protons in anhydroxylose units [31, 70]. Typical peeks are assigned to functional groups in lignin, as shown in Table $3[25,31]$. 
TABLE 2: Assignments of signals in FTIR spectrum to functional groups in lignin $[25,29,38]$.

\begin{tabular}{|c|c|c|}
\hline Wavenumbers $/ \mathrm{cm}^{-1}$ & Assignments & Functional groups and structures in lignin \\
\hline $3400-3600$ & $v(\mathrm{O}-\mathrm{H})$ & Free $-\mathrm{OH}$ \\
\hline $3100-3400$ & $v(\mathrm{O}-\mathrm{H})$ & Associated $-\mathrm{OH}$ \\
\hline $2820-2960$ & $v(\mathrm{C}-\mathrm{H})$ & $-\mathrm{CH}_{2},-\mathrm{CH}_{3}$ \\
\hline 2920 & $v(\mathrm{C}-\mathrm{H})$ & Carboxylic $-\mathrm{OH}$ \\
\hline $2650-2890$ & $v(\mathrm{C}-\mathrm{H})$ & Methyl group in methoxyl \\
\hline 1771 & $v(\mathrm{C}=\mathrm{O})$ & Aromatic \\
\hline $1700-1750$ & $v(\mathrm{C}=\mathrm{O})$ & Unconjugated ketones, carbonyls, and ester groups \\
\hline 1722 & $v(\mathrm{C}=\mathrm{O})$ & Aliphatic \\
\hline $1650-1680$ & $v(\mathrm{C}=\mathrm{O})$ & Conjugated $p$-substituent carbonyl and carboxyl \\
\hline $1500-1600,1420-1430$ & $v$ (aromatic skeletal) & Benzene ring \\
\hline $1450-1470,1360-1370$ & $v(\mathrm{C}-\mathrm{H})$ & $-\mathrm{CH}_{2},-\mathrm{CH}_{3}$ \\
\hline $1325-1330,1230-1235$ & $v(\mathrm{C}-\mathrm{O})$ & Syringyl ring \\
\hline $1270-1275$ & $v(\mathrm{C}-\mathrm{O})$ & Guaiacyl ring \\
\hline 1215 & $v(\mathrm{C}-\mathrm{O})$ & Ether \\
\hline $1140-1145$ & $v(\mathrm{C}-\mathrm{H})$ & Guaiacyl \\
\hline 1130 & $v(\mathrm{C}-\mathrm{H})$ & Syringyl \\
\hline $1085-1090$ & $v(\mathrm{C}-\mathrm{O})$ & Secondary alcohol and aliphatic ether \\
\hline $1025-1035$ & $v(\mathrm{C}-\mathrm{O}, \mathrm{C}-\mathrm{H})$ & Aromatic ring and primary alcohol \\
\hline $750-860$ & $v(\mathrm{C}-\mathrm{H})$ & Aromatic ring \\
\hline
\end{tabular}

TABle 3: Assignments of signals in ${ }^{1} \mathrm{H}$ NMR spectrum to typical functional groups in lignin (in $\mathrm{CD}_{3} \mathrm{Cl}$ ) $[25,31]$.

\begin{tabular}{lc}
\hline Chemical shift/ppm & Assignments \\
\hline $9.7-9.9$ & Cinamaldehydes and benzaldehydes \\
$6.7-7.1$ & Aromatic- $\mathrm{H}$ in guaiacyl \\
$6.2-6.7$ & Aromatic-H in syringyl \\
$5.8-6.2$ & Benzylic $\mathrm{OH}$ in $\beta-\mathrm{O}-4$ and $\beta-1$ \\
$4.9-5.1$ & Carbohydrates \\
$3.3-4.0$ & Methoxyl \\
$3.0-3.1$ & $\mathrm{H}_{\beta}$ in $\beta-1$ \\
$2.2-2.4$ & Phenolic $\mathrm{OH}$ \\
$1.6-2.2$ & Aliphatic $\mathrm{OH}$ \\
\hline
\end{tabular}

${ }^{13} \mathrm{C}$ NMR can be carried out to overcome the overlapping resonances of some structures in ${ }^{1} \mathrm{H}$ NMR spectra, providing qualitative and quantitative results with nondestructive detection of solid or solution samples. Although with a higher resolution, it is recommended that relative pure lignin sample is necessary in the ${ }^{13} \mathrm{C}$ NMR analysis, since the unexpected overlapping of spectra was due to the complexity of sample. Typical ${ }^{13} \mathrm{C}$ NMR spectra are shown in Figure 5 [31], and the assignments of signals are presented in Table $4[31,38,49,71]$. By using the data from quantitative ${ }^{13} \mathrm{C}$ NMR, basic parameters which summarizes the main structural characteristics of lignins can be obtained, such as content of $\beta-\mathrm{O}-4$ structures, degree of condensation, and unit ratio of $\mathrm{S} / \mathrm{G} / \mathrm{H}$. Radar plots include these parameters and allow a direct classification of different lignins by comparison of the key descriptors [71]. Solid-state ${ }^{13} \mathrm{C}$ NMR analysis is a nondestructive method and not limited by sample insolubility. The cross-polarization/magic angle spinning (CP/MAS) method extensively used NMR technique for elucidating the structure of lignin. The detections take a very short time with high resolution; however, the quantitative analysis of $\mathrm{CP} / \mathrm{MAS}$ is not sufficient enough [72]. Solid-state ${ }^{13} \mathrm{C}$ NMR is considered to be an advanced method for structural investigation of LCBM at atomic level; however, by using this technique, the structure remains largely unexplored due to the complexity of lignin and the severe spectral crowding of the responding signals [73]. A sensitive hyperpolarization solid-state NMR technique by combining highfield dynamic nuclear polarization (DNP) and MAS was used to improve the resolution of the determination [74]. Furthermore, this technique can provide 2D homonuclear ${ }^{13} \mathrm{C}-{ }^{13} \mathrm{C}$ correlation solid-state NMR spectra at natural isotopic abundance, yielding, and an atomic level structural investigation $[75,76]$. Most of current lignin content analytical techniques require solo or sequential degradation or dissociation steps, which are time-consuming. By using the solid-state ${ }^{13} \mathrm{C} \mathrm{CP} / \mathrm{MAS} \mathrm{NMR}$ technique with an internal standard (sodium-3-trimethylsilylpropionate, TMSP), a simple yet reliable method was established to analyze content of lignin in various LCBMs without destroying their native structures [77].

Constant et al. [78] carried out the quantification and classification of carbonyls in industrial humins and lignins by ${ }^{19} \mathrm{~F}$ NMR. The carbonyl groups were transformed to corresponding hydrazone with 4-(trifluoromethyl)phenylhydrazine before quantification by ${ }^{19} \mathrm{~F}$ NMR. By using model compound library, the carbonyl functional groups in Indulin Kraft and Alcell lignins were quantified and classified for the first time. 

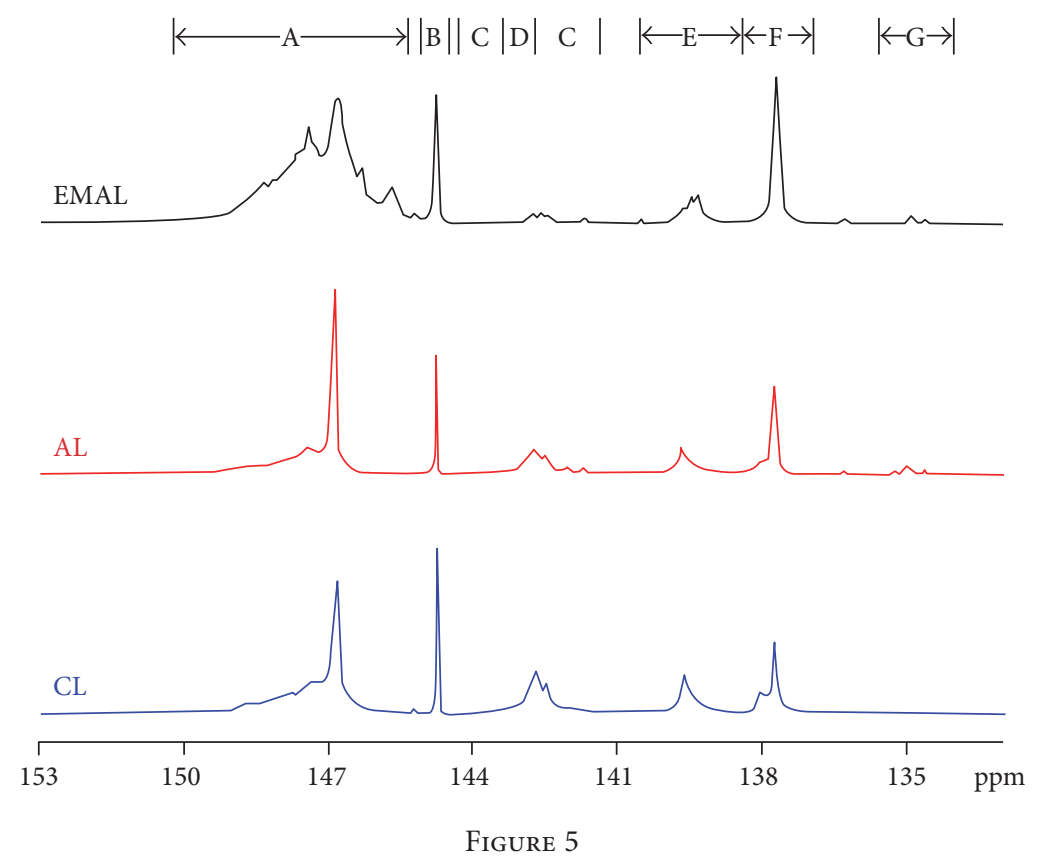

TABLE 4: Assignments of signals in ${ }^{13} \mathrm{C}$ NMR spectrum to functional groups in lignin $[31,38,49,71]$.

\begin{tabular}{lc}
\hline Chemical shift/ppm & Assignments \\
\hline $167-178$ & Unconjugated -COOH \\
$162-168$ & Conjugated -COOH \\
$140-155$ & $\mathrm{C}_{3}, \mathrm{C}_{4}$ aromatic ether or hydroxyl \\
$127-140$ & $\mathrm{C}_{1}$, aromatic C-C \\
$123-127$ & $\mathrm{C}_{5}$, aromatic C-C \\
$117-123$ & $\mathrm{C}_{6}$, aromatic C-H \\
$114-117$ & $\mathrm{C}_{5}$, aromatic C-H \\
$106-114$ & $\mathrm{C}_{2}$, aromatic C-H \\
$78-90$ & Aliphatic $\mathrm{C}_{\beta}-\mathrm{O}$ \\
$67-78$ & Aliphatic $\mathrm{C}_{\alpha}-\mathrm{O}$ \\
$54-57.5$ & Methoxyl \\
\hline
\end{tabular}

${ }^{31} \mathrm{P}$ NMR has also been widely used to quantitatively determine the amount of aliphatic and phenolic hydroxyl groups as well as carboxyl groups in lignin after phosphitylation with 2-chloro-4,4,5,5-tetramethyl-1,3,2-dioxaphospholane (TMDP) $[29,79,80]$. The high phenolic OH content reflecting the presence of condensed aromatic units, such as 5-5 units, was found by ${ }^{31} \mathrm{P}$ NMR in a biolignin produced by acetic acid/formic acid/water hydrolysis from wheat straw [81]. The ${ }^{31} \mathrm{P}$ NMR analysis of the insoluble fraction of $\mathrm{kraft}$ lignin provided an accurate and quantitative way to illustrate the effects of the laccase-HBT (1-hydroxybenzotriazole) system on lignin chemical bond cleavage [82]. Typical ${ }^{31} \mathrm{P} N M R$ spectra and signal assignments are shown in Figure 6 and Table 5, respectively $[29,82]$.

Solid-/solution-state ${ }^{13} \mathrm{C}$ NMR spectroscopes are powerful in lignin structural elucidation either in their solid or solution state. However, solid-state ${ }^{13} \mathrm{C}$ NMR spectroscopy is only suitable for the analysis of lignin samples that have restricted solubility and can observe some structural features of lignin due to its low resolution; and lignin is subjected to acetylation by anhydride/pyridine solution before the solution-state ${ }^{13} \mathrm{C}$ NMR spectrum collection [83] since dissolving lignin is difficult.

Various 2D NMR methods were carried out to overcome the overlapping of resonances in $1 \mathrm{D}$ NMR with higher resolution and providing more reliability to the assignments of the signals, especially in the determination of lignin [44, 84-93]. 2D NMR methods, such as heteronuclear multiple-quantum coherence (HMQC) spectroscopy, heteronuclear correlation (HETCOR) spectroscopy, homonuclear Hartmann-Hahn (HOHAHA) spectroscopy, total correlation spectroscopy (TOCSY), rotating frame Overhauser experiment spectroscopy (ROESY), heteronuclear singlequantum coherence (HSQC) spectroscopy, and heteronuclear multiple bond coherence (HMBC) spectroscopy, have been employed in lignin structure characterization [44, 84-86]. Among these, 2D HSQC NMR is the most extensively used due to its versatility in illustrating structural features and structural transformations of isolated lignin fractions. Figure 7 presents a typical investigation of lignin with accurate assignments of different structures [71]. 2D HSQC NMR is able to clearly characterize the structures of lignin and polysaccharides in cell walls and the linkages among the lignin without isolating each component [87]. Structural changes of lignin and the other components in LCBM in chemical reaction can be easily monitored by this method. The relationship between the degree of acetylation and the introduction positions of acetyl groups during the acetylation of ground pulp was investigated with 2D HSQC NMR [88]. Acetylation was found to occur firstly on the primary hydroxyl groups of polysaccharides and lignin, followed by the secondary hydroxyl groups of polysaccharides, and finally the hydroxyl groups at the $\alpha$-position in lignin [88]. 


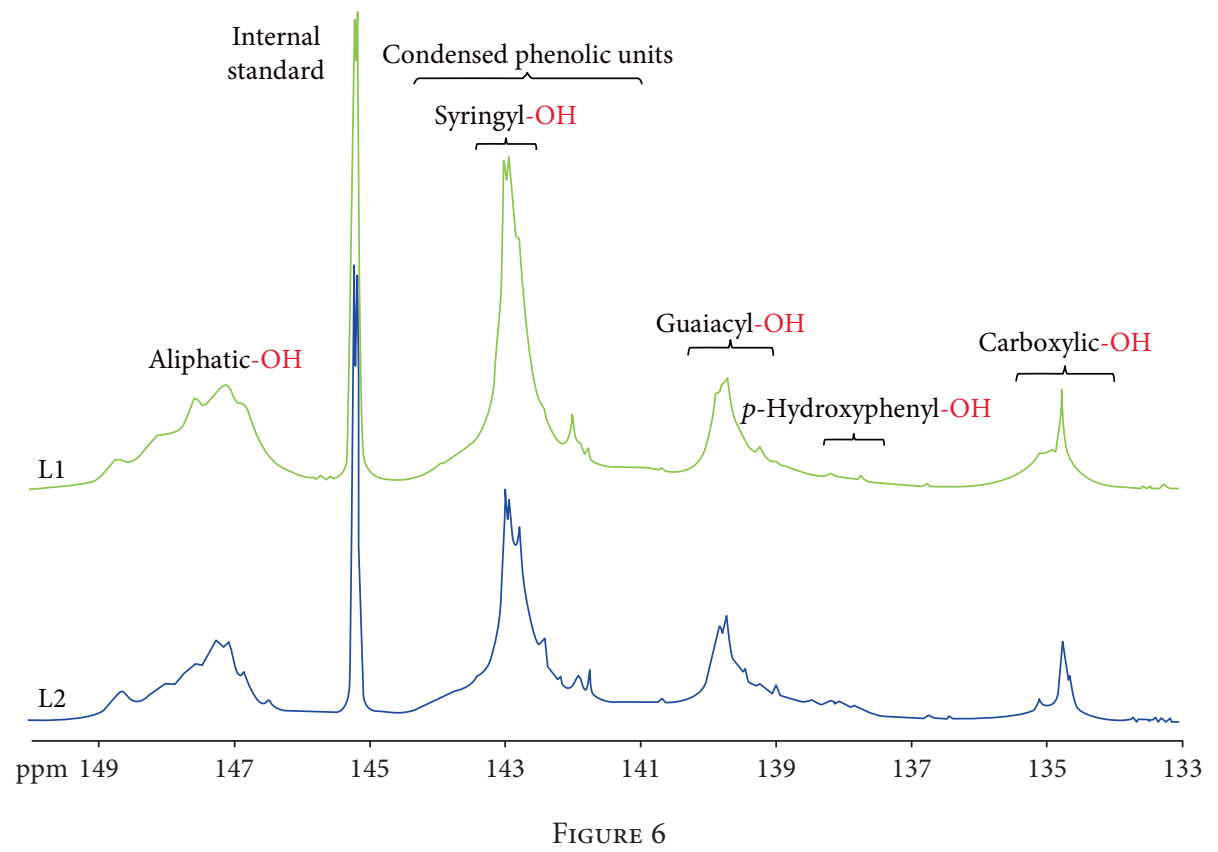

TABle 5: Assignments of signals in ${ }^{31} \mathrm{P}$ NMR spectrum to hydroxyl groups in lignin $[29,82]$.

\begin{tabular}{lc}
\hline Chemical shift/ppm & Structural assignments \\
\hline $145.5-150.0$ & Aliphatic -OH \\
$136.5-144.7$ & Phenols \\
$140.0-144.5$ & $\mathrm{C}_{5}$ substituted \\
143.5 & $\beta-5$ \\
142.7 & Syringyl \\
142.3 & $4-\mathrm{O}-5$ \\
141.2 & $5-5$ \\
$139.0-140.0$ & Guaiacyl \\
$138.2-139.0$ & Catechol \\
$137.3-138.2$ & p-Hydroxyphenyl \\
$133.6-136.6$ & Carboxylic acid -OH \\
\hline
\end{tabular}

Thioacidolysis was usually used as pretreatment before $2 \mathrm{D}$ HSQC NMR analysis in the characterization of the structures of the lignin monomers and oligomers [89]. Changes in the interunit linkage types during solvolysis were investigated. Lignin oligomers ranging from monomers to tetramers were released through considerable cleavage of the $\beta$-O- 4 linkages [89]. In a study of various lignins derived from brewer's spent grain, 2D HSQC NMR revealed the substructures including $\beta$-O-4' alkyl-aryl ethers (77-79\%), $\beta-5^{\prime}$ phenylcoumarans (11-13\%), $\beta-\beta^{\prime}$ resinols (5-6\%), and 5-5' dibenzodioxocins (3-5\%); while 2D HMBC NMR and derivatization followed by reductive cleavage analyses showed that $p$-coumarates were acylating at the $\gamma$-position of lignin side chains and were mostly occurred in condensed structures [90]. By using high-resolution 2D HSQC NMR, the chemical structures both on low and high molecular weight fractions of biooil derived from kraft lignin were determined. In the degradation of kraft lignin to bio-oil, cleavages of both aliphatic carbon-oxygen (C-O) and to some extent carboncarbon (C-C) bonds as well as repolymerization were observed simultaneously [91].

The combination of quantitative ${ }^{13} \mathrm{C}$ NMR and $2 \mathrm{D}$ HSQC NMR has been proven to be a powerful way in structural elucidation of complex samples since it takes advantage of the spectral dispersion afforded by the $2 \mathrm{D}$ spectrum to serve as an internal standard to measure the integral values obtained from the quantitative ${ }^{13} \mathrm{C}$ spectrum [92]. This method can overcome the severe overlap of signals and reduce errors in signal quantification due to differential line widths, quantitative abundance of $\mathrm{S} / \mathrm{G} / \mathrm{H}$ units, hydroxycinnamates, and tricin units, as well as various types of side chain substructures by selecting the proper internal standard reference signals [93]. Other combinations of NMR techniques were also reported; for instance, the existence of low energy dipole-dipole interactions and the absence of covalent bond between lignin and chitosan could be revealed clearly by solid-state ${ }^{1} \mathrm{H}^{13} \mathrm{C}$ CP/MAS NMR [94].

\section{Conclusions}

The comprehensive understanding of the lignin structure relies greatly on the developments of analytical strategies used, which is extremely important for the value-added utilization of biomass. Although significant progresses have been made in the degradation and isolation of the lignin from other components in LCBM, only a fraction of lignin can be identified and analyzed. Structure and composition of lignins from different LCBMs vary significantly according to both issue and age. Furthermore, the analytical results are strongly dependent on the degradation processes and instrumental equipment used.

For the structural investigation of lignin, undestroyed, selective, and efficient isolation methods should be built to 

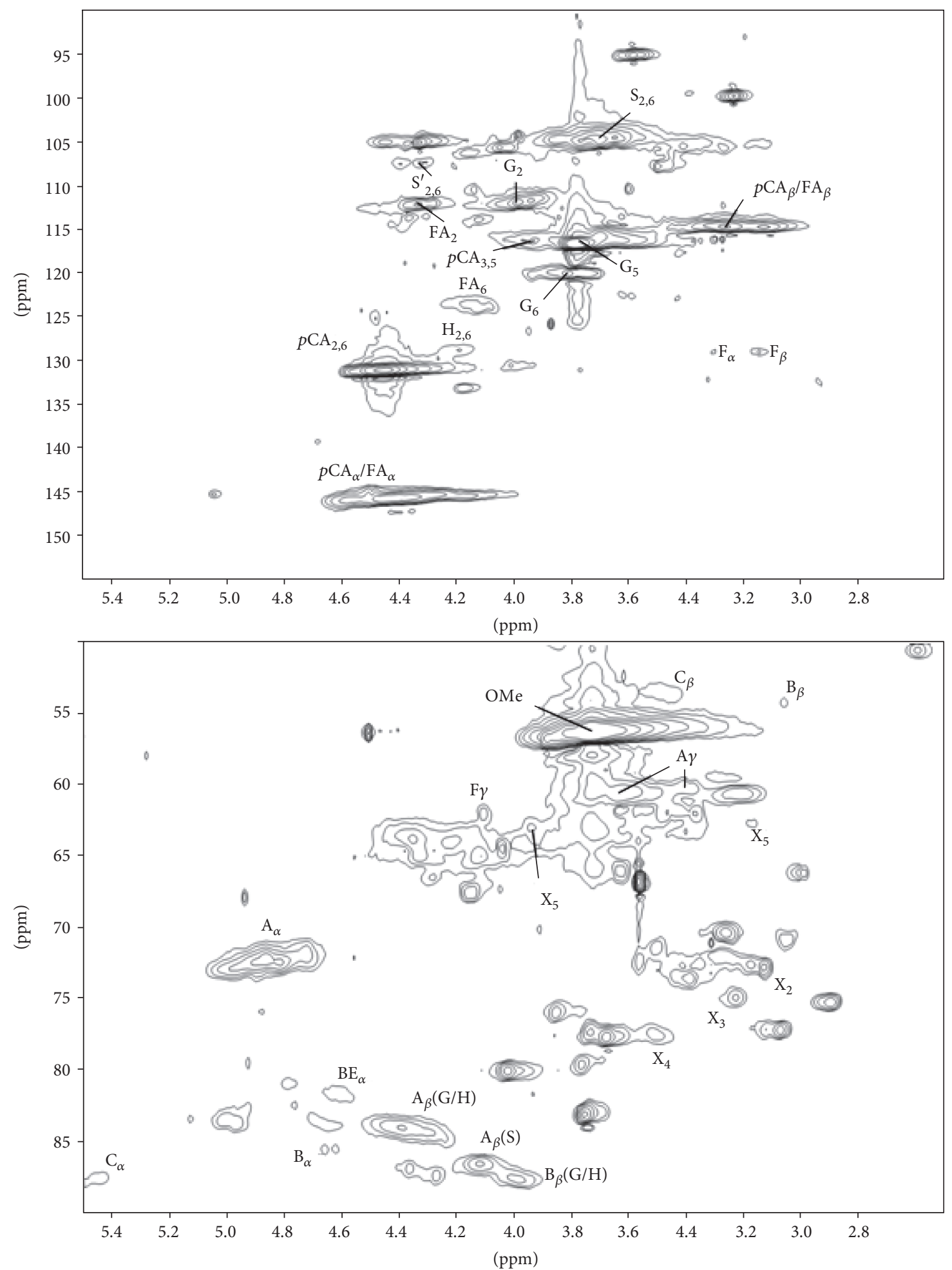

Figure 7

preserve the initial structure of lignin and obtain as much sample to be analyzed. Among the wet-chemistry techniques used, IL extraction and organosolv process are the promising methods. They are treated as environmentally friendly methods since relatively mild conditions used and the reagents can be recycled. Biological degradation might be another possible pathway for the oriented isolation of lignin since the outstanding selectivity and rate of conversion.

Various spectroscopic methods are routinely used for the investigation of lignin structures. These methods can provide both qualitative and quantitative information on functional groups and linkages in lignin as well as degradation products 
of lignin. Among these spectroscopic techniques, UV spectroscopy is less likely to be used since it can provide relatively less information on the structural features of lignin. Generally, FTIR spectroscopy is much more frequently used than Raman spectroscopy. FTIR, ${ }^{1} \mathrm{H}$ NMR, and ${ }^{13} \mathrm{C}$ NMR are commonly used in most of the investigations for the characterization of structure of lignins. Recently, ${ }^{31} \mathrm{P}$ NMR is more adopted in this area. Significant progresses for structural elucidation of lignin rely on the application of quantitative ${ }^{13} \mathrm{C}$ NMR and various $2 \mathrm{D}$ NMRs. They are robust techniques by providing detailed qualitative and quantitative results with high resolution and precision and can be treated as ideal methods. Rapid, accurate, and nondestructive spectroscopic techniques can be combined to overcome their individual intrinsic limitations for better elucidation of lignin structure. The data collected from these methods contributes to the understanding of LCBM structure and facilitates the design of effective processes to obtain ligninbased value-added chemicals.

\section{Conflicts of Interest}

The authors declare that there is no conflict of interest regarding the publication of this paper.

\section{Acknowledgments}

This work was supported by the Fundamental Research Funds for the Central Universities (Grant 2015XKMS100), the National Natural Science Foundation of China (Grant nos. 21506250 and 21676293), and the Qing Lan Project of Jiangsu Province (awarded in 2017).

\section{References}

[1] J. S. Luterbacher, D. M. Alonso, and J. A. Dumesic, "Targeted chemical upgrading of lignocellulosic biomass to platform molecules," Green Chemistry, vol. 16, pp. 4816-4838, 2014.

[2] B. M. Upton and A. M. Kasko, "Strategies for the conversion of lignin to high-value polymeric materials: review and perspective," Chemical Reviews, vol. 116, no. 4, pp. 2275-2306, 2016.

[3] K. M. N. Satheesh, A. K. Mohanty, L. Erickson, and M. Misra, "Lignin and its applications with polymers," Journal of Biobased Materials and Bioenergy, vol. 3, pp. 1-24, 2009.

[4] D. Stewart, "Lignin as a base material for materials applications: chemistry, applications and economics," Industrial Crops and Products, vol. 27, no. 2, pp. 202-207, 2008.

[5] C. R. Poovaiah, M. Nageswara-Rao, J. R. Soneji, H. L. Baxter, and C. N. Stewart Jr, "Altered lignin biosynthesis using biotechnology to improve lignocellulosic biofuel feedstocks," Plant Biotechnology Journal, vol. 12, pp. 1163-1173, 2014.

[6] H. B. C. Molinari, T. K. Pellny, J. Freeman, P. R. Shewry, and R. A. C. Mitchell, "Grass cell wall feruloylation: distribution of bound ferulate and candidate gene expression in Brachypodium distachyon," Frontiers in Plant Science, vol. 4, p. 50, 2013.

[7] J. Shigeto, Y. Ueda, S. Sasaki, K. Fujita, and Y. Tsutsumi, "Enzymatic activities for lignin monomer intermediates highlight the biosynthetic pathway of syringyl monomers in Robinia pseudoacacia," Journal of Plant Research, vol. 130, no. 1, pp. 203-210, 2017.
[8] A. L. Healey, J. S. Lupoi, D. J. Lee et al., "Effect of aging on lignin content, composition and enzymatic saccharification in Corymbia hybrids and parental taxa between years 9 and 12," Biomass and Bioenergy, vol. 93, pp. 50-59, 2016.

[9] D. Kai, M. J. Tan, P. L. Chee, Y. K. Chua, Y. L. Yap, and X. J. Loh, "Towards lignin-based functional materials in a sustainable world," Green Chemistry, vol. 18, no. 5, pp. 1175-1200, 2016.

[10] Y. Zeng, M. E. Himmel, and S. Y. Ding, "Coherent Raman microscopy analysis of plant cell walls," Methods in Molecular Biology, vol. 908, pp. 49-60, 2012.

[11] C. Zhou, Q. Li, V. L. Chiang, L. A. Lucia, and D. P. Griffis, "Chemical and spatial differentiation of syringyl and guaiacyl lignins in poplar wood via time-of-flight secondary ion mass apectrometry," Analytical Chemistry, vol. 83, no. 18, pp. 7020-7026, 2011.

[12] S. Jung, M. Foston, U. C. Kalluri, G. A. Tuskan, and A. J. Ragauskas, "3D chemical image using TOF-SIMS revealing the biopolymer component spatial and lateral distributions in biomass," Angewandte Chemie International Edition, vol. 51, no. 48, pp. 12005-12008, 2012.

[13] A. J. Ragauskas, G. T. Beckham, M. J. Biddy et al., "Lignin valorization: improving lignin processing in the biorefinery," Science, vol. 344, no. 6185, article 1246843, 2014.

[14] A. P. Dodd, J. F. Kadla, and S. K. Straus, "Characterization of fractions obtained from two industrial softwood kraft lignins," ACS Sustainable Chemistry \& Engineering, vol. 3, no. 1, pp. 103-110, 2015.

[15] N. Giummarella, L. M. Zhang, G. Henriksson, and M. Lawoko, "Structural features of mildly fractionated lignin carbohydrate complexes (LCC) from spruce," RSC Advances, vol. 6, no. 48, pp. 42120-42131, 2016.

[16] H. L. Wang, H. X. Ben, H. Ruan et al., "Effects of lignin structure on hydrodeoxygenation reactivity of pine wood lignin to valuable chemicals," ACS Sustainable Chemistry \& Engineering, vol. 5, no. 2, pp. 1824-1830, 2017.

[17] A. Berlin and M. Balakshin, "Industrial lignins: analysis, properties, and applications," in Bioenergy Research: Advances and Applications, V. K. Gupta, M. G. T. P. Kubicek and J. S. Xu, Eds., pp. 315-336, Elsevier, Amsterdam, 2014.

[18] R. Prado, A. Brandt, X. Erdocia, J. Hallet, T. Welton, and J. Labidi, "Lignin oxidation and depolymerisation in ionic liquids," Green Chemistry, vol. 18, no. 3, pp. 834-841, 2016.

[19] J. Shi, S. Pattathil, R. Parthasarathi et al., "Impact of engineered lignin composition on biomass recalcitrance and ionic liquid pretreatment efficiency," Green Chemistry, vol. 18, no. 18, pp. 4884-4895, 2016.

[20] Y. Lu, X. Y. Wei, J. P. Cao et al., "Characterization of a bio-oil from pyrolysis of rice husk by detailed compositional analysis and structural investigation of lignin," Bioresource Technology, vol. 116, pp. 114-119, 2012.

[21] S. Z. Wang, X. Fan, A. L. Zheng et al., "Evaluation of the oxidation of rice husks with sodium hypochlorite using gas chromatography-mass spectrometry and direct analysis in real time-mass spectrometry," Analytical Letters, vol. 47, no. 1, pp. 77-90, 2014.

[22] X. Fan, J. L. Zhu, A. L. Zheng et al., "Rapid characterization of heteroatomic molecules in a bio-oil from pyrolysis of rice husk using atmospheric solid analysis probe mass spectrometry," Journal of Analytical and Applied Pyrolysis, vol. 115, pp. 1623, 2015. 
[23] V. V. Lobodin, L. Nyadong, B. M. Ruddy et al., "Fourier transform ion cyclotron resonance mass spectrometry for analysis of complex organic mixtures," International Journal of Mass Spectrometry, vol. 378, pp. 186-192, 2015.

[24] C. F. Wang, X. Fan, F. Zhang et al., "Characterization of humic acids extracted from a lignite and interpretation for the mass spectra," RSC Advances, vol. 7, no. 33, pp. 2067720684, 2017.

[25] T. T. You and F. Xu, "Applications of molecular spectroscopic methods to the elucidation of lignin structure," Applications of Molecular Spectroscopy to Current Research in the Chemical and Biological Sciences, vol. 2016, pp. 235-260.

[26] E. A. Capanema, M. Y. Balakshin, and J. F. Kadla, "A comprehensive approach for quantitative lignin characterization by NMR spectroscopy," Journal of Agricultural and Food Chemistry, vol. 52, no. 7, pp. 1850-1860, 2004.

[27] B. Jiang, T. Y. Cao, F. Gu, W. J. Wu, and Y. C. Jin, "Comparison of the structural characteristics of cellulolytic enzyme lignin preparations isolated from wheat straw stem and leaf," ACS Sustainable Chemistry \& Engineering, vol. 5, no. 1, pp. 342-349, 2017.

[28] C. Zhao, S. Xie, Y. Pu et al., "Synergistic enzymatic and microbial conversion of lignin for lipid," Green Chemistry, vol. 18, no. 5, pp. 1306-1312, 2016.

[29] B. Ahvazi, É. Cloutier, O. Wojciechowicz, and T. D. Ngo, "Lignin profiling: a guide for selecting appropriate lignins as precursors in biomaterials development," ACS Sustainable Chemistry \& Engineering, vol. 4, no. 10, pp. 5090-5105, 2016.

[30] M. Yáñez-S, B. Matsuhiro, C. Nuñez et al., "Physicochemical characterization of ethanol organosolv lignin (EOL) from Eucalyptus globulus: effect of extraction conditions on the molecular structure," Polymer Degradation and Stability, vol. 110, pp. 184-194, 2014.

[31] Q. Wang, S. S. Liu, G. L. Yang, and J. C. Chen, "Characterization of high-boiling-solvent lignin from hot-water extracted bagasse," Energy \& Fuels, vol. 28, no. 5, pp. 3167-3171, 2014.

[32] M. B. Whitfield, M. S. Chinn, and M. W. Veal, "Improvement of acid hydrolysis procedures for the composition analysis of herbaceous biomass," Energy \& Fuels, vol. 30, no. 10, pp. 8260-8269, 2016.

[33] W. H. Gong, Z. Y. Xiang, F. Y. Ye, and G. H. Zhao, "Composition and structure of an antioxidant acetic acid lignin isolated from shoot shell of bamboo (Dendrocalamus latiforus)," Industrial Crops and Products, vol. 91, pp. 340-349, 2016.

[34] W. Zhang, N. Sathitssuksanoh, B. A. Simmons, C. E. Frazier, J. R. Barone, and S. Renneckar, "Revealing the thermal sensitivity of lignin during glycerol thermal processing through structural analysis," RSC Advances, vol. 6, no. 36, pp. 3023430246, 2016.

[35] A. E. Harman-Ware, C. Foster, R. M. Happs et al., "A Thioacidolysis method tailored for higher-throughput quantitative analysis of lignin monomers," Journal of Biotechnology, vol. 11, no. 10, pp. 1268-1273, 2016.

[36] J. L. Wen, S. L. Sun, B. L. Xue, and R. C. Sun, "Quantitative structures and thermal properties of birch lignins after ionic liquid pretreatment," Journal of Agricultural and Food Chemistry, vol. 61, no. 3, pp. 635-645, 2013.

[37] B. J. Cox and J. G. Ekerdt, "Pretreatment of yellow pine in an acidic ionic liquid: extraction of hemicelluloses and lignin to facilitate enzymatic digestion," Bioresource Technology, vol. 134, pp. 59-65, 2013.
[38] A. Casas, M. Oliet, M. V. Alonso, and F. Rodrígues, "Dissolution of Pinus radiata and Eucalyptus globulus woods in ionic liquids under microwave radiation: lignin regeneration and characterization," Separation and Purification Technology, vol. 97, pp. 115-122, 2012.

[39] S. S. Mohtar, T. N. Z. Tengku Malim Busu, A. M. Md Noor, N. Shaari, and H. Mat, "An ionic liquid treatment and fractionation of cellulose, hemicelluloses and lignin from oil palm empty fruit bunch," Carbohydrate Polymers, vol. 166, pp. 291-299, 2017.

[40] T. Rashid, C. F. Kait, I. Regupathi, and T. Murugesan, "Dissolution of kraft lignin using protic ionic liquids and characterization," Industrial Crops and Products, vol. 84, pp. 284-293, 2016.

[41] Y. X. An, N. Li, H. Wu, W. Y. Lou, and M. H. Zong, "Changes in the structure and the thermal properties of kraft lignin during its dissolution in cholinium ionic liquids," ACS Sustainable Chemistry \& Engineering, vol. 3, no. 11, pp. 2951-2958, 2015.

[42] S. Nanayakkara, A. F. Patti, and K. Saito, "Lignin depolymerization with phenol via redistribution mechanism in ionic liquids," ACS Sustainable Chemistry \& Engineering, vol. 2, no. 9, pp. 2159-2164, 2014.

[43] J. X. Long, W. Y. Lou, L. F. Wang, B. L. Yin, and X. H. Li, " $\left[\mathrm{C}_{4} \mathrm{H}_{8} \mathrm{SO}_{3} \mathrm{Hmim}\right] \mathrm{HSO}_{4}$ as an efficient catalyst for direct liquefaction of bagasse lignin: decomposition properties of the inner structural units," Chemical Engineering Science, vol. 122, pp. 24-33, 2015.

[44] S. G. Khokarale, T. Le-That, and J. P. Mikkola, "Carbohydrate free lignin: a dissolution-recovery cycle of sodium lignosulfonate in a switchable ionic liquid system," ACS Sustainable Chemistry \& Engineering, vol. 4, no. 12, pp. 7032-7040, 2016.

[45] A. Mittal, R. Katahira, B. S. Donohoe et al., "Ammonia pretreatment of corn stover enables facile lignin extraction," ACS Sustainable Chemistry \& Engineering, vol. 5, no. 3, pp. 2544-2561, 2017.

[46] T. Q. Yuan, T. T. You, W. Wang, F. Xu, and R. C. Sun, "Synergistic benefits of ionic liquid and alkaline pretreatments of poplar wood. Part 2: characterization of lignin and hemicelluloses," Bioresource Technology, vol. 136, pp. 345-350, 2013.

[47] Y. C. Sun, M. Wang, and R. C. Sun, “Toward an understanding of inhomogeneities in structure of lignin in green solvents biorefinery. Part 1: fractionation and characterization of cignin," ACS Sustainable Chemistry \& Engineering, vol. 3, no. 10, pp. 2443-2451, 2015.

[48] C. Nitsos, R. Stoklosa, A. Karnaouri et al., "Isolation and characterization of organosolv and alkaline lignins from hardwood and softwood biomass," ACS Sustainable Chemistry \& Engineering, vol. 4, no. 10, pp. 5181-5193, 2016.

[49] L. N. Yang, D. M. Wang, D. Zhou, Y. W. Zhang, and T. T. Yang, "Isolation and further structural characterization of lignins from the valonea of Quercus variabilis," International Journal of Biological Macromolecules, vol. 97, pp. 164-172, 2017.

[50] L. N. Yang, D. M. Wang, D. Zhou, and Y. Zhang, "Effect of different isolation methods on structure and properties of lignin from valonea of Quercus variabilis," International Journal of Biological Macromolecules, vol. 85, pp. 417-424, 2016.

[51] S. Zhou, Y. Xue, A. Sharma, and X. L. Bai, "Lignin valorization through thermochemical conversion: comparison of hardwood, softwood and herbaceous lignin," ACS 
Sustainable Chemistry \& Engineering, vol. 4, no. 12, pp. 6608-6617, 2016.

[52] G. T. Beckham, C. W. Johnson, E. M. Karp, D. Salvachúa, and D. R. Vardon, "Opportunities and challenges in biological lignin valorization," Current Opinion in Biotechnology, vol. 42, pp. 40-53, 2016.

[53] F. Xu, R. C. Sun, M. Z. Zhai, J. X. Sun, J. X. Jiang, and G. J. Zhao, "Comparative study of three lignin fractions isolated from mild ball-milled Tamarix austromogoliac and Caragana sepium," Journal of Applied Polymer Science, vol. 8, no. 2, pp. 1158-1168, 2008.

[54] A. Sluiter, B. Hames, R. Ruiz et al., Determination of Structural Carbohydrates and Lignin in Biomass, National Renewable Energy Laboratory (NREL) Laboratory Analytical Procedures (LAP) for Standard Biomass Analysis, National Renewable Energy Laboratory, Golden, USA, 2007, NREL/TP-510-42618.

[55] F. Q. Xiong, Y. M. Han, S. Q. Wang et al., "Preparation and formation mechanism of renewable lignin hollow nanospheres with a single hole by self-assembly," ACS Sustainable Chemistry \& Engineering, vol. 5, no. 3, pp. 2273-2281, 2017.

[56] B. Hansen, P. Kusch, M. Schulze, and B. Kamm, "Qualitative and quantitative analysis of lignin producedfrom beech wood by different conditions of the organosolv process," Journal of Polymers and the Environment, vol. 24, no. 2, pp. 85-97, 2016.

[57] S. O. Prozil, D. V. Evtuguin, A. M. S. Silva, and L. P. C. Lopes, "Structural characterization of lignin from grape stalks (Vitis vinifera L.)," Journal of Agricultural and Food Chemistry, vol. 62, no. 24, pp. 5420-5428, 2014.

[58] M. Azadfar, H. M. GaoA, M. V. Bule, and S. L. Chen, "Structural characterization of lignin: a potential source ofantioxidants guaiacol and 4-vinylguaiacol," International Journal of Biological Macromolecules, vol. 75, pp. 58-66, 2015.

[59] K. A. Y. Koivu, H. Sadeghifar, P. A. Nousiainen, D. S. Argyropoulos, and J. Sipilä, "Effect of fatty acid esterification on the thermal properties of softwood kraft lignin," ACS Sustainable Chemistry \& Engineering, vol. 4, no. 10, pp. 5238-5247, 2016.

[60] Q. L. Yang, J. B. Shi, and L. Lin, "Characterization of structural changes of lignin in the process of cooking of bagasse with solid alkali and active oxygen as a pretreatment for lignin conversion," Energy \& Fuels, vol. 26, pp. 6999-7004, 2012.

[61] I. Santoni, E. Callone, A. Sandak, J. Sandak, and S. Dirè, "Solid state NMR and IR characterization of wood polymer structure in relation to tree provenance," Carbohydrate Polymers, vol. 117, pp. 710-721, 2015.

[62] L. Passauer, K. Salzwedel, M. Struch, N. Herold, and J. Appelt, "Quantitative analysis of the etherification degree of phenolic hydroxyl groups in oxyethylated lignins: correlation of selective aminolysis with FTIR spectroscopy," ACS Sustainable Chemistry \& Engineering, vol. 4, no. 12, pp. 6629-6637, 2016.

[63] U. P. Agarwal, R. S. Reiner, A. K. Pandey, S. A. Ralph, K. C. Hirth, and R. H. Atalla, Eds., "Raman spectra of lignin model compounds," in 59th Appita Annual Conference and Exhibition: Incorporating the 13th ISWFPC (International Symposium on Wood, Fiber and Pulping Chemistry), Auckland, New Zealand, 16-19 May 2005: Proceedings, Appita Inc., 2005.

[64] K. L. Larsen and S. Barsberg, "Environmental effects on the lignin model monomer, vanillyl alcohol, studied by Raman spectroscopy," Journal of Physical Chemistry B, vol. 115, no. 39, pp. 11470-11480, 2011.
[65] B. I. Na, S. J. Chang, K. H. Lee, G. Lee, and J. W. Lee, "Characterization of cell wall structure in dilute acidpretreated biomass by confocal Raman microscopy and enzymatic hydrolysis," Biomass and Bioenergy, vol. 93, pp. 33-37, 2016.

[66] J. Ralph, C. Lapierre, F. C. Lu et al., "NMR evidence for benzodioxane structures resulting from incorporation of 5hydroxyconiferyl alcohol into lignins of O-methyltransferasedeficient poplars," Journal of Agricultural and Food Chemistry, vol. 49, no. 7, pp. 86-91, 2001.

[67] L. M. Zhang, G. Gellerstedt, J. Ralph, and L. F. C. , "NMR studies on the occurrence of spirodienone structures in lignins," Journal of Wood Chemistry and Technology, vol. 26, no. 1, pp. 65-79, 2006.

[68] G. Wang and H. Chen, "Fractionation and characterization of lignin from steam-exploded corn stalk by sequential dissolution in ethanol-water solvent," Separation and Purification Technology, vol. 120, pp. 402-409, 2013.

[69] C. Fernández-Costas, S. Gouveia, M. A. Sanromán, and D. Moldes, "Structural characterization of kraft lignins from different spent cooking liquors by $1 \mathrm{D}$ and 2D nuclear magnetic resonance spectroscopy," Biomass and Bioenergy, vol. 63, pp. 156-166, 2014.

[70] L. L. An, G. H. Wang, H. Y. Jia, C. Y. Liu, W. J. Sui, and C. L. Si, "Fractionation of enzymatic hydrolysis lignin by sequential extraction for enhancing antioxidant performance," International Journal of Biological Macromolecules, vol. 99, pp. 674681, 2017.

[71] C. A. Esteves Costa, W. Coleman, M. Dube, A. E. Rodrigues, and P. C. Rodrigues Pinto, "Assessment of key features of lignin from lignocellulosic crops: stalks and roots of corn, cotton, sugarcane, and tobacco," Industrial Crops and Products, vol. 92, pp. 136-148, 2016.

[72] H. Ben and A. J. Ragauskas, "Torrefaction of loblolly pine," Green Chemistry, vol. 14, no. 1, pp. 72-76, 2012.

[73] T. Wang, P. Phyo, and M. Hong, "Multidimensional solidstate NMR spectroscopy of plant cell walls," Solid State Nuclear Magnetic Resonance, vol. 78, pp. 56-63, 2016.

[74] D. Lee, S. Hediger, and G. De Paepe, "Is solid-state NMR enhanced by dynamic nuclear polarization?," Solid State Nuclear Magnetic Resonance, vol. 66-67, pp. 6-20, 2015.

[75] G. Mollica, M. Dekhil, F. Ziarelli, P. Thureau, and S. Viel, "Quantitative structural constraints for organic powders at natural isotopic abundance using dynamic nuclear polarization solid-state NMR spectroscopy," Angewandte Chemie International Edition, vol. 54, no. 20, pp. 6028-6031, 2015.

[76] F. A. Perras, H. Luo, X. M. Zhang, N. S. Mosier, M. Pruski, and M. M. Abu-Omar, "Atomic-level structure characterization of biomass pre- and post-lignin treatment by dynamic nuclear polarization-enhanced solid-state NMR," Journal of Physical Chemistry A, vol. 121, no. 3, pp. 623-630, 2017.

[77] X. Gao, D. D. Laskar, J. J. Zeng, G. L. Helms, and S. L. Chen, “A ${ }^{13} \mathrm{C}$ CP/MAS-based nondegradative method for lignin content analysis," ACS Sustainable Chemistry \& Engineering, vol. 3, no. 1, pp. 153-162, 2015.

[78] S. Constant, C. S. Lancefield, B. M. Weckhuysen, and P. C. Bruijnincx, "Quantification and classification of carbonyls in industrial humins and lignins by ${ }^{19} \mathrm{~F}$ NMR," ACS Sustainable Chemistry \& Engineering, vol. 5, no. 1, pp. 965-972, 2017.

[79] Y. Pu, S. Cao, and A. J. Ragauskas, "Application of quantitative ${ }^{31} \mathrm{P}$ NMR in biomass lignin and biofuel precursors 
characterization," Energy \& Environmental Science, vol. 4, no. 9, pp. 3154-3166, 2011.

[80] S. D. Springer, J. He, M. Chui, R. D. Little, M. Foston, and A. Butler, "Peroxidative oxidation of lignin and a lignin model compound by a manganese SALEN derivative," ACS Sustainable Chemistry \& Engineering, vol. 4, no. 6, pp. 3212-3219, 2016.

[81] L. Mbotchak, C. L. Morvan, K. L. Duong, B. Roussear, M. Tessier, and A. Fradet, "Purification, structural characterization, and modification of organosolv wheat straw lignin," Journal of Agricultural and Food Chemistry, vol. 63, no. 21, pp. 5178-5188, 2015.

[82] S. X. Xie, Q. N. Sun, Y. Q. Pu et al., "Advanced chemical design for efficient lignin bioconversion," ACS Sustainable Chemistry \& Engineering, vol. 5, no. 3, pp. 2215-2223, 2017.

[83] F. C. Lu and J. Ralph, "Non-degradative dissolution and acetylation of ball-milled plant cell walls: high-resolution solution-state NMR," The Plant Journal, vol. 35, no. 4, pp. 535-544, 2003.

[84] J. J. Bozell, C. J. O’Lenick, and S. Warwick, "Biomass fractionation for the biorefinery: heteronuclear multiple quantum coherence-nuclear magnetic resonance investigation of lignin isolated from solvent fractionation of switchgrass," Journal of Agricultural and Food Chemistry, vol. 59, no. 17, pp. 92329242, 2011.

[85] Y. Le Brech, L. Delmotte, J. Raya, N. Brosse, R. Gadiou, and A. Dufour, "High resolution solid state 2D NMR analysis of biomass and biochar," Analytical Chemistry, vol. 87, no. 2, pp. 843-847, 2015.

[86] Y. Le Brech, J. Raya, L. Delmotte, N. Brosse, R. Gadiou, and A. Dufour, "Characterization of biomass char formation investigated by advanced solid state NMR," Carbon, vol. 108, pp. 165-177, 2016.

[87] D. Ando, F. Nakatsubo, T. Takano, and H. Yano, "Elucidation of LCC bonding sites via $\gamma$-TTSA lignin degradation: crude milled wood lignin (MWL) from Eucalyptus globulus for enrichment of lignin xylan linkages and their HSQC-NMR characterization," Holzforschung, vol. 70, no. 6, pp. 489-494, 2016.

[88] D. Ando, F. Nakatsubo, and H. Yano, "Acetylation of ground pulp: monitoring acetylation via HSQC-NMR spectroscopy," ACS Sustainable Chemistry \& Engineering, vol. 5, no. 2, pp. 1755-1762, 2017.

[89] K. Saito, A. Kaiho, R. Sakai, H. Nishimura, H. Okada, and T. Watanabe, "Characterization of the interunit bonds of lignin oligomers released by acid-catalyzed selective solvolysis of Cryptomeria japonica and Eucalyptus globulus woods via thioacidolysis and 2D-NMR," Journal of Agricultural and Food Chemistry, vol. 64, no. 48, pp. 9152-9160, 2016.

[90] J. Rencoret, P. Prinsen, A. Gutiérrez, Á. T. Martínez, and J. C. del Río, "Isolation and structural characterization of the milled wood lignin, dioxane lignin, and cellulolytic lignin preparations from brewer's spent grain," Journal of Agricultural and Food Chemistry, vol. 63, no. 2, pp. 603613, 2015.

[91] C. Mattsson, S. I. Andersson, T. Belkheiri et al., "Using 2D NMR to characterize the structure of the low and high molecular weight fractions of bio-oil obtained from lignoBoost ${ }^{\mathrm{TM}}$ kraft lignin depolymerized in subcritical water," Biomass and Bioenergy, vol. 95, pp. 364-377, 2016.

[92] L. Zhang and G. Gellerstedt, "Quantitative 2D HSQC NMR determination of polymer structures by selecting suitable internal standard references," Magnetic Resonance in Chemistry, vol. 45, no. 1, pp. 37-45, 2007.

[93] J. J. Zeng, G. L. Helms, X. Gao, and S. L. Chen, "Quantification of wheat straw lignin structure by comprehensive NMR analysis," Journal of Agricultural and Food Chemistry, vol. 61, no. 46, pp. 10848-10857, 2013.

[94] K. Crouvisier-Urion, P. R. Bodart, P. Winckler et al., "Biobased composite films from chitosan and lignin: antioxidant activity related to structure and moisture," ACS Sustainable Chemistry \& Engineering, vol. 4, no. 12, pp. 6371-6381, 2016. 

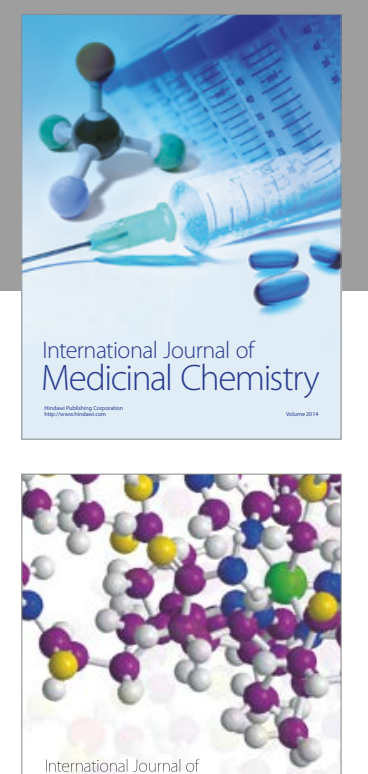

Carbohydrate Chemistry

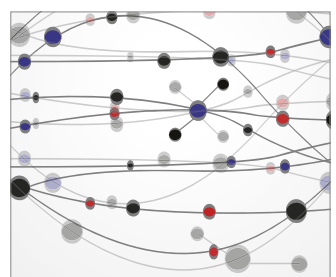

The Scientific World Journal
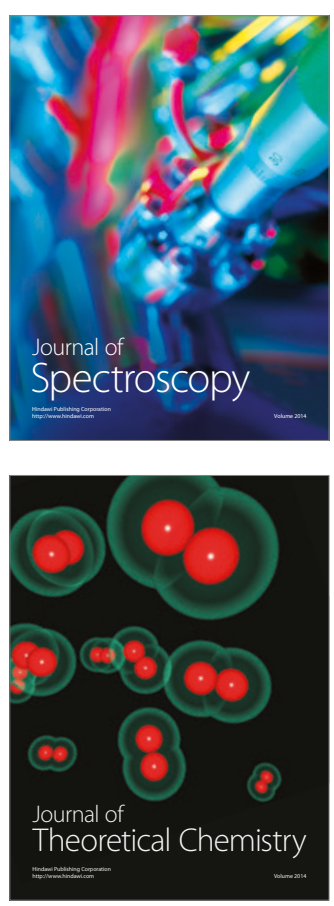
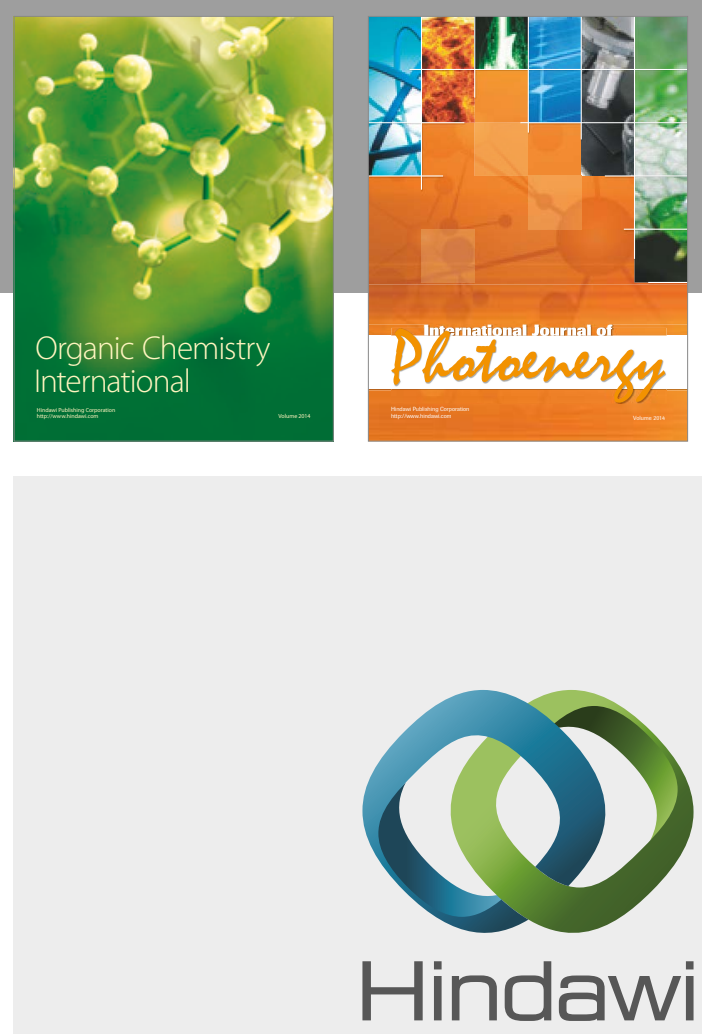

Submit your manuscripts at

https://www.hindawi.com

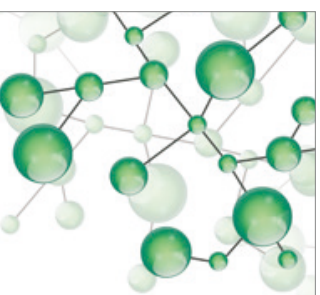

International Journal of

Inorganic Chemistry

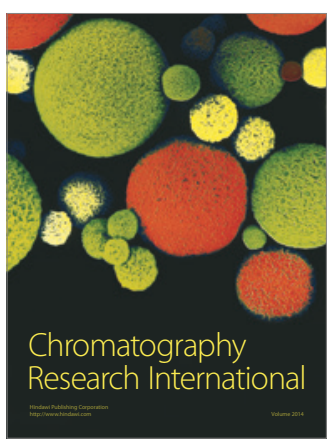

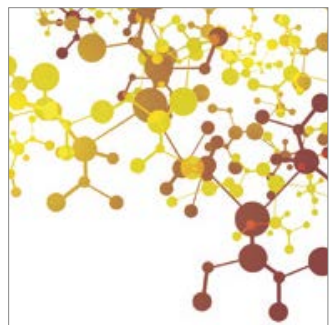

Applied Chemistry
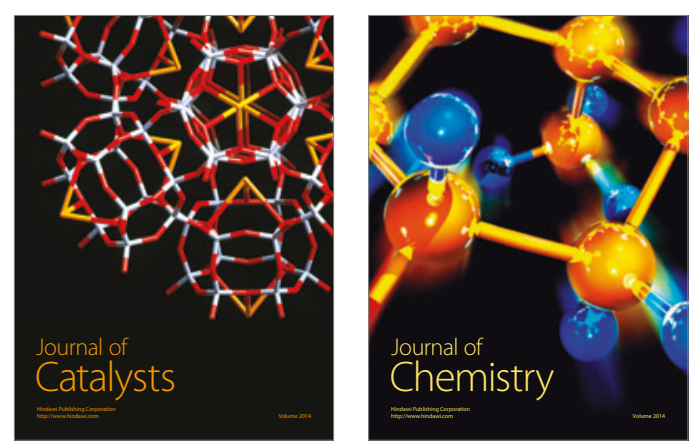
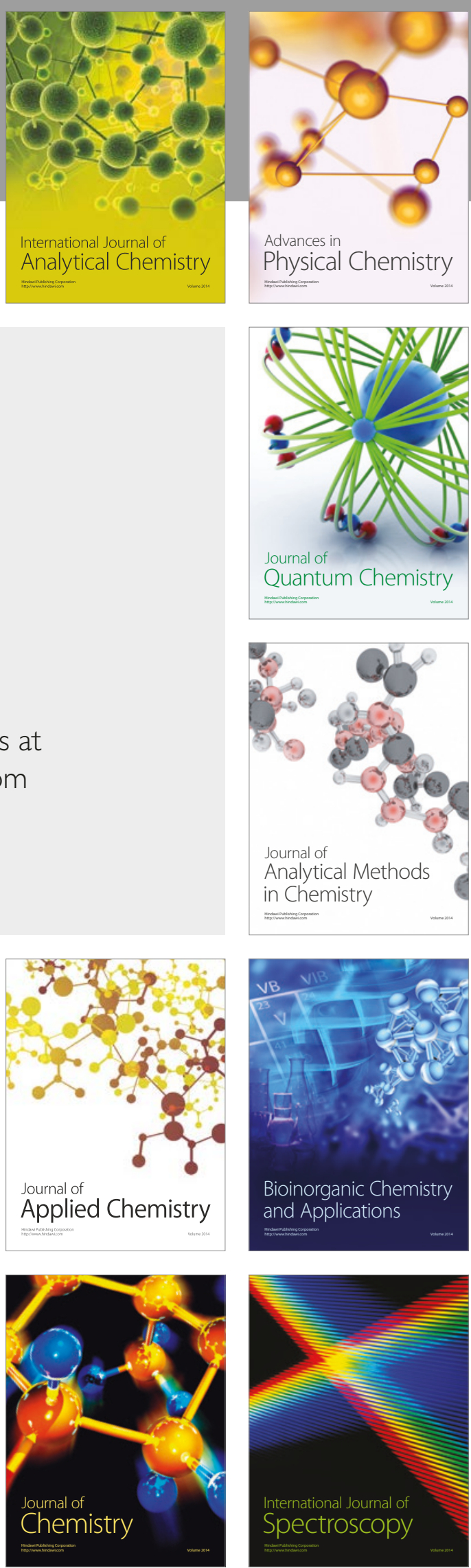